\title{
Integration of gastric distension and gustatory responses in the parabrachial nucleus
}

\author{
JOHN-PAUL BAIRD, SUSAN P. TRAVERS, AND JOSEPH B. TRAVERS \\ Oral Biology, College of Dentistry, Ohio State University, Columbus, Ohio 43210
}

Received 25 January 2001; accepted in final form 10 July 2001

\begin{abstract}
Baird, John-Paul, Susan P. Travers, and Joseph B. Travers. Integration of gastric distension and gustatory responses in parabrachial nucleus. Am J Physiol Regulatory Integrative Comp Physiol 281: R1581-R1593, 2001.Palatable gustatory stimuli promote feeding, whereas gastric distension generally inhibits this behavior. We explored a neural basis for integration of these opposing sensory signals by evaluating the effect of gastric distension on gustatory responses in the parabrachial nucleus (PBN) of anesthetized rats. Sixteen percent of 92 taste cells were coactivated; they responded to independent taste or gastric distension stimulus application. Modulation of taste responses by distension was more prevalent; taste responses declined $37 \%$ in response to distension in $25 \%$ of the cells and increased by $46 \%$ in $10 \%$ of cells. Across the whole population, however, the suppressive effect of distension on taste responses was small (6\%). The incidence of modulation did not vary as a simple hedonic function of gustatory sensitivity, i.e., similar proportions of sucrose-, citric-acid-, and QHCl-best, but not NaClbest, neurons were modulated by gastric distension. Coactivated, modulated, and nonmodulated gustatory-responsive cells were intermingled in the gustatory zone of the caudal $\mathrm{PBN}$. The suppression of $\mathrm{PBN}$ taste responses by visceral stimulation may reflect a mechanism for satiation and further implicates the PBN in the control of ingestive function.
\end{abstract}

nucleus of the solitary tract; electrophysiology; satiation; satiety; rat; stomach

THE INTEGRATION OF TASTE and postingestive feedback signals is fundamental to feeding behavior. Indeed, the progress of meal taking has been modeled as a function of the changing balance of taste (excitatory) and postingestive (inhibitory) feedback signals derived throughout the meal $(11-14,57)$. For example, when gut accumulation of food is prevented during feeding through redirection of ingesta via an open gastric fistula ("sham feeding"), oral food intake is grossly elevated because of a lack of feedback inhibition (reviewed in Ref. 55). Conversely, taste reactivity is significantly diminished when rats are given a gastric load before taste sampling (8, also see Ref. 32). Yet, only a handful of studies have begun to uncover the neurophysiological concomitants of taste-gut integration (e.g., Refs. 24, $33,40,51)$.

Although areas throughout the brain have been implicated in taste-visceral processing, interpretation of

Address for reprint requests and other correspondence: J.-P. Baird, Oral Biology, College of Dentistry, P.O. Box 182357, 305 W. 12th Ave., Columbus, OH 43218-2357 (E-mail: baird.84@osu.edu). integration involving sensory, mnemonic, conditioned, and motivational factors that occurs in forebrain regions (see Ref. 51 for a review) may be clarified by understanding the initial integration of afferent stimuli (27). A brain stem locus for basic taste-visceral integration is implicated because chronic decerebrate rats, in which all neural connections between the forebrain and the brain stem are severed, can nonetheless modify intake of a sapid stimulus after a gastric preload (30, 54).

In the brain stem, both vagal visceral and taste afferent fibers synapse within the nucleus of the solitary tract (NST; for review, see Refs. 47 and 52), but they have a spatially distinct representation. Although previous investigators $(20-24,26)$ have reported that taste responses in the NST are modulated by longerterm postingestive treatments, such as sustained gastric distension or venous glucose infusions, it is not clear whether these effects result from primary afferent integration per se or from more indirect, perhaps hormonal, influences. In fact, Hermann et al. (37) failed to find coactivation of NST neurons during paired electrical gustatory and vagal stimulation.

There is, however, considerable neuroanatomical (35, 40, 46) and lesion/behavioral (e.g., Refs. 50 and 56) evidence to suggest that afferent signals from the oral cavity and the gastrointestinal tract are integrated in the parabrachial nucleus of the pons (PBN), which receives overlapping projections from the rostral (taste) and caudal (visceral) regions of the NST. The most direct confirmation of this integration is from electrophysiological studies. Hermann and Rogers (36) found single $\mathrm{PBN}$ units responsive to oral $\mathrm{NaCl}$ and to electrical vagal or caudal NST stimulation. Although provocative, the findings are limited because the visceral stimulus was not specific, and, moreover, only one tastant was applied to the anterior tongue, excluding the majority of taste receptors and three common taste qualities (59). However, recent work by Hajnal and colleagues (33) provides further insight into PBN integrative processes. They showed in awake rats that $\mathrm{PBN}$ neural responses to intraoral sucrose and $\mathrm{NaCl}$ were significantly diminished $\sim 10$ min after a duodenal intralipid infusion.

The costs of publication of this article were defrayed in part by the payment of page charges. The article must therefore be hereby marked "advertisement" in accordance with 18 U.S.C. Section 1734 solely to indicate this fact. 
In the present study, we used acute extracellular techniques to record responses of single PBN gustatory neurons to separate and conjoint applications of oral taste stimuli and gastric distension. Gastric distension represents a different visceral stimulus than that tested by Hajnal and colleagues (33). Unlike caloric stimuli, distension is rapidly reversible, thereby allowing repeated measurements in the same cell. Because the integration tests using distension are brief $(<1$ min), indirect mediation via hormonal contingencies is less likely than with caloric stimuli. In addition, the rapid reversibility of distension permits the following two forms of integration to be assessed: coactivation, as shown by Hermann and Rogers (36; a separate response to visceral and taste stimulation), and modulation (a change in the taste response during visceral stimulation despite no overt response to visceral stimulation), as shown by Hajnal et al. (33).

\section{METHODS}

\section{Subjects}

Fifty-four male Sprague-Dawley rats (Harlan) weighing $348.5 \pm 5.3(\mathrm{SE}) \mathrm{g}$ (range $=290-440)$ at the time of surgery were tested. Rats were maintained in individual plastic tubs on a 12:12-h light-dark schedule. Food (Purina Rat Chow no. 5001) and water were available ad libitum. Rats were injected for surgery at the same time each day, $\sim 3 \mathrm{~h}$ after lights on. All procedures were approved by the Institutional Animal Care and Use Committee.

\section{Surgery}

Rats were anesthetized with Nembutal ( $50 \mathrm{mg} / \mathrm{kg}$ ip), with supplementary doses to maintain a nonreflexive level of anesthesia. On occasion, rats were pretreated with ethyl carbamate $(1.0 \mathrm{~g} / \mathrm{kg})$ to prolong the viability of the experiment. All surgeries were performed under aseptic conditions. Core temperature was regulated by a rectal thermometer and adjustments to a heating pad.

The visceral surgery was based on protocols established in many previous gastric recording studies (e.g., Refs. 2, 4, 16, $17,26,40,58)$. A laparotomy was made, and the antrum was exposed. Gastric contents were removed via a small incision, and a gastric balloon was inserted gently toward the corpus region. The balloon was made from a latex glove finger and was fastened via Teflon tape to one end of a Tygon tube (1/32 in. ID, 3/32 in. OD). The wound was ligated around the balloon's shaft. The stomach was then viewed via a surgical microscope over a range of balloon inflation volumes to ensure proper function and to evaluate possible tissue damage. If small tears (typically $\sim 1 \mathrm{~mm}$, perpendicular to the longitudinal axis) were observed, inflation was immediately halted, and larger inflation values were not tested. The laparotomy was then closed, a tracheotomy was performed, and an oral drain tube was inserted along with retractable mouth sutures to expose the oral cavity (34). The rat was then placed in a stereotaxic frame, and the skull was exposed and leveled. The left hemisphere was trephined $1.7 \mathrm{~mm}$ lateral and $0.4 \mathrm{~mm}$ anterior to lambda to expose $\sim 15 \mathrm{~mm}^{2}(5$ $\mathrm{mm} \times 3 \mathrm{~mm}$ ) of brain surface, allowing full access to the PBN. The left side was tested because the left NST receives dominant innervation by the hepatic vagal branch, which carries gastric-antral fibers within it $(1,6)$.

\section{Stimulation and Recording}

Taste stimuli were delivered to the whole mouth from two pipettes fed by a pressurized solenoid-controlled manifold fluid delivery system. One pipette was directed at the nasoincisor ducts, and the stream of the other was directed over the whole tongue surface. Previous studies from this laboratory have shown that this method is adequate to evoke responses from the anterior tongue, nasoincisor ducts, soft palate, and foliate papillae and occasionally suffices to evoke responses from the circumvallate papilla (34). Fluid delivery was controlled by a computer program to achieve precise coordination of gustatory and visceral stimuli. An infusion/ withdrawal pump (model 210P; KD Scientific) controlled by a computer program was used to deliver gastric stimuli. The gastric balloon was connected to a 140-ml syringe. Fluid stimuli initially included $\mathrm{dH}_{2} \mathrm{O}, 0.3 \mathrm{M} \mathrm{NaCl}$, and $0.3 \mathrm{M}$ sucrose (appetitive stimuli) and $0.01 \mathrm{M} \mathrm{HCl}$ and $0.003 \mathrm{M}$ QHCl (aversive stimuli). An undiluted "taste mixture" containing each of these tastants served as a "probe" taste stimulus for searching. Because initial experiments yielded few $\mathrm{HCl}$-best neurons, $\mathrm{HCl}$ was replaced with $0.05 \mathrm{M}$ citric acid after one-third of the rats had been tested. In addition, the concentration of $\mathrm{NaCl}$ was reduced to $0.1 \mathrm{M}$, and the tastant, $0.1 \mathrm{M} \mathrm{NH}_{4} \mathrm{Cl}$, was also added to the test battery to better discriminate broadly tuned electrolyte-responsive cells from neurons more narrowly tuned to sodium salts (45). Analyses based on taste quality were restricted to cells tested using the final stimulus array. Gastric volumes tested spanned the "normal range" of distension (see Ref. 4), and noxious volumes were avoided. For the current study, 6, 12, and $18 \mathrm{ml}$ were selected as "anchor" volumes for initial testing. In about one-third of rats, $18 \mathrm{ml}$ was not tested because it produced tissue damage.

Recording. Glass- and parylene-coated tungsten microelectrodes [impedance $(\mathrm{Z})=0.5-2.5 \mathrm{M} \Omega$; conical tips $\sim 7 \mu \mathrm{m} \times$ $\sim 15 \mu \mathrm{m}$ (base $\times$ height)] were used to record extracellular activity of single neurons in the PBN. Neural activity was amplified, monitored on a storage oscilloscope, and stored on magnetic tape. Stimulus markers were recorded on separate channels. Data were simultaneously collected using the MII (Modular Instruments Systems) or Spike2 (Cambridge Electronic Design) systems.

Search procedure. The electrode was inclined $20^{\circ}$ posteriorly to prevent transverse sinus rupture and was advanced automatically using a piezoelectric microdrive. Once the brain stem was encountered, neural responses were evaluated in $25-\mu \mathrm{m}$ increments. The taste mixture, followed by rinsing, was used as a search stimulus. The gastric probe stimulus was $6 \mathrm{ml}$ air distension. Jaw stretch was tested by depressing the lower incisors. If a jaw stretch response was observed (indicating the mesencephalic trigeminal nucleus), the electrode was withdrawn and a new track was started. Oral tactile responses were evaluated using a glass probe to stroke the anterior tongue, foliate region, and occasionally the soft palate. Tracks were made at $100-$ to $200-\mu \mathrm{m}$ points along a grid over the exposed region of the brain surface.

Stimulation protocol. GUSTATORY STIMULATION. If a single neuron responsive to the taste mixture was detected, the single most effective taste stimulus was evaluated. Taste stimulation (10 s) was preceded by a 30 -s unstimulated period, the middle $10 \mathrm{~s}$ of which was the "spontaneous" period for data analysis. After taste offset $(10 \mathrm{~s})$, a $\mathrm{dH}_{2} \mathrm{O}$ rinse was applied for $20 \mathrm{~s} \mathrm{(34),} \mathrm{followed} \mathrm{by} \mathrm{a} 50$-s rest interval. Taste stimuli were presented in the order sucrose, $\mathrm{NaCl}, \mathrm{HCl}$ (or citric acid), $\mathrm{QHCl}, \mathrm{NH}_{4} \mathrm{Cl}$, and $\mathrm{dH}_{2} \mathrm{O}$. Taste stimuli and $\mathrm{dH}_{2} \mathrm{O}$ were individually tested ( $2 \mathrm{~min}$ each), up to three times 
each. If the "best" taste response was not clear, replications of suspected best stimuli were conducted.

DISTENSION STIMULATION. Cells were then tested for a response to gastric distension at $6 \mathrm{ml}$. The balloon was inflated for $10 \mathrm{~s}$, held fully inflated for $10 \mathrm{~s}$, and then deflated for $10 \mathrm{~s}$. Gastric stimulation was preceded by $30 \mathrm{~s}$ of baseline recording and was followed by a $90-\mathrm{s}$ pause. If no response was noted at $6 \mathrm{ml}$, then $12 \mathrm{ml}$ was also tested. If there was a distension response, replications of the three gastric anchor volumes were conducted at least two times each as follows: 6 , 12 , and $18 \mathrm{ml}$ (if possible). If this protocol was completed, 3-, 9 -, and 15-ml (if possible) volumes were then tested.

MODUlation TESTING. Modulation was then evaluated by testing the best gustatory stimulus before, during, and after applying the best gastric stimulus ( $6 \mathrm{~min} / \mathrm{test}$ ). Modulation tests consisted of three taste tests [a "before" (taste only), "during" (taste + gastric), and "after" (taste only) distension taste test]. The before and after taste tests were identical in structure to those described for a single taste test. For the during condition, taste and gastric stimuli were presented simultaneously; thus, after the spontaneous period, the stomach was inflated for $10 \mathrm{~s}$. Once full inflation was achieved, the taste stimulus was applied for $10 \mathrm{~s}$. For the next $10 \mathrm{~s}$, the stomach was deflated. For the next $20 \mathrm{~s}$, a water rinse was applied, followed by an interstimulus interval of $120 \mathrm{~s}$.

Cells were usually tested for modulation using $6 \mathrm{ml}$ and 12 $\mathrm{ml}$ one time each. If modulation was suspected, replications were conducted, and an 18-ml modulation test was added (if this volume was testable). In a subset of cells $(n=16)$, we also performed "mock" modulation tests that were identical to modulation tests, except that the gastric stimulus was not applied. After modulation tests, if the cell remained isolated, additional replications of the taste-gastric modulation sequence were conducted at the same or different volumes.

Histological reconstruction. A lesion (anodal current: 3 $\mu \mathrm{A} \times 3 \mathrm{~s}$ ) was usually made at the recording site or subjacent to it. Concluding testing, the rat was given a lethal dose of anesthetic and was perfused with isotonic saline followed by $10 \%$ buffered formalin. The brain was blocked in the recording plane, removed, and sectioned. Alternate sections were stained with Weil and cresyl violet to distinguish myelinated fibers from somatic components.

Neurophysiological data analysis. Electrophysiological data were analyzed off-line. Response measures used were the net spike counts during the stimulation period. Net spike counts were derived by subtracting the spike count during the spontaneous period before a given stimulation from the spike count during the stimulation period. All periods were matched in duration ( $10 \mathrm{~s})$. For gastric stimulation, measurements were derived for three 10 -s periods, during "inflation," "hold," and "deflation." Responses were considered significant if they satisfied the appropriate criteria described below.

GUSTATORY AND GASTRIC RESPONSES. To be regarded as a significant taste response, the net response elicited by gustatory stimuli had to exceed $2 \mathrm{SD}$ of the mean spontaneous rate for all spontaneous periods evaluated for that cell. In addition, the taste response had to exceed any response to $\mathrm{dH}_{2} \mathrm{O}$ by at least $100 \%$ (i.e., two times the water response). Gustatory-responsive neurons were considered to be coactivated by gastric stimuli if the net response for any one of the three 10-s distension periods (inflation, hold, or deflation) exceeded $2 \mathrm{SD}$ of the mean spontaneous rate for that cell, or, for inhibitory responses, the net spike total fell below $50 \%$ of the spontaneous rate.

MODULATED GUSTATORY RESPONSES. Although studies have used various criteria to evaluate changes in neural taste/ visceral responses after treatment (modulation; see Refs. 2,
$15,22,33,61$ ), we approached the issue empirically by evaluating mock modulation tests in a subset of cells ( $n=$ 16). For these 16 neurons, the mean of the absolute percent change from the "mock before" to the "mock during" stimulation was $10.5 \%$ and from the "mock before" to the "mock after" period was $12.5 \%$. Thus the criterion for a taste "modulation" in actual distension tests was defined as a taste response change of $25 \%$ from baseline in either the during or after distension taste test, which is two times the average variation seen across repeated "taste-only" tests, i.e., mock trials. This criterion is thus analogous to our criteria for significant taste and gastric responses.

To simplify the modulation analysis, we selected one modulation test for each cell, the modulation test that used the most effective taste stimulus for that cell at the largest volume tested. Thus 71/92 cells had a modulation test using the most effective taste stimulus. For 4 of these cells this volume was $6 \mathrm{ml}$; for 2 cells, $9 \mathrm{ml}$; for 51 cells, $12 \mathrm{ml}$; for 1 cell, $15 \mathrm{ml}$; and for 13 cells, $18 \mathrm{ml}$. If a cell had multiple modulation tests at the same tastant and distension volume $(n=35)$, we used the average values across tests. Cells that were not used for analysis either had no modulation test $(n=13)$ or were tested for modulation using a tastant that was not the optimal stimulus for the cell ( $n=8$; also see Table 1$)$.

\section{Statistical Analysis}

Electrophysiology. For hierarchical cluster analysis, the Pearson product-moment correlation coefficient and averagelinkage methods were used to calculate taste profile similarities in cells tested using the final taste stimulus array $(n=$ 55). Pearson correlations were also used to compare responses in coactivated neurons (net response to taste vs. net response to distension). Modulation effects across the population were evaluated using ANOVA. $\chi^{2}$ analysis was used to determine if the chemosensitivity of neurons was systematically related to whether or not they showed modulation.

Histology. Recording sites were plotted on one of four representative serial sections of $\mathrm{PBN}$, each section $\sim 200 \mu \mathrm{m}$ apart. If a lesion was made at the recording site before the electrode was moved for further sampling, then the cell could be localized within morphologically distinct PBN subnuclei $(19,34)$. However, if the lesion was not made at the recording site or was made at the site upon removal of the electrode, the precise location in the dorsoventral axis could not be specified because of factors such as tissue hysteresis and shrinkage. In the present study, we restricted our histological analysis to gustatory neurons marked with lesions at the recording site. In addition to analyzing the anatomical distribution of gustatory neurons, we also compared their locations with the distribution of a population of gastric-responsive neurons recorded in an earlier study (4). Because fewer neurons in the gastric study were marked with lesions at the recording site,

\section{Table 1. Summary of neurons recorded}

Count

\begin{tabular}{ll}
\hline Overall & \\
Cells recorded & 92 \\
Cells tested for coactivation & 92 \\
Cells tested for modulation & 71 \\
Coactivated cells tested for modulation & 12 \\
Noncoactivated cells tested for modulation & 59 \\
Gustatory coding & 55 \\
Cells tested using final taste battery & 55 \\
Cells tested for coactivation & 38 \\
Cells tested for modulation &
\end{tabular}


we included cells with lesions made on the same track that were no more than $250 \mu \mathrm{m}$ distant from the site to have an adequate sample for comparison. $\chi^{2}$ analyses were used to evaluate whether neurons were differentially distributed according to their response characteristics.

\section{RESULTS}

Out of 92 taste cells only a small proportion showed a reliable response to gastric distension. For the most part, the effects of distension on these "coactivated" cells was inhibitory, although a few excitatory responses were observed. A greater proportion of cells, however, showed an appreciable modulation of taste responsivity by distension in the absence of a clear distension response per se. Table 1 shows which groups of cells were tested for coactivation and/or modulation.

\section{Coactivated Taste Cells}

Sixteen percent of the taste cells (15/92) exhibited an independent response to distension and were thus considered coactivated (e.g., Fig. 1). Gastric responses were generally inhibitory, and the taste responses were generally excitatory (Fig. 2, inset). Across coactivated cells, the mean response evoked by distension was significantly smaller than that evoked by taste; however, the response magnitude for distension responses was generally consistent with other reports in the PBN (e.g., Refs. 4 and 58). In coactivated neurons, distension evoked a $1.8 \pm 0.4$ net spikes/s suppression, whereas taste effected a $10.5 \pm 3.7 \mathrm{spikes} / \mathrm{s}$ increase $[t(14)=2.30, P<0.04]$. Interestingly, the magnitude of the best taste response in coactivated cells was small compared with that for distension-insensitive taste cells; all but three coactivated cells had taste response rates below the median (Fig. 2).

\section{Modulated Taste Responses}

For 71/92 taste cells, we were able to test the modulatory effects of gastric distension on the response to the "best" tastant (Table 1). Across the population, the inhibitory effect of distension was small (6\%) but statistically significant $[F(2,140)=3.24, P<0.04]$. In contrast, the spontaneous rate preceding each of the test periods (before, during, and after stomach inflation) did not vary significantly $[F(2,140)=2.19$, not significant (NS)], suggesting that the decline in responsiveness was not the result of a general decrement in firing rate during the recording session. Similarly, it is important to point out that the decline in responsiveness related to gastric distension was not simply the result of an effect of repeated taste stimulation. Sixteen cells were evaluated with mock distension trials, and there was no significant difference across mock before, during, and after taste trials; the mean response during mock distension declined by just $2 \%$ $[F(2,32)=0.37, \mathrm{NS}]$. By comparison, for the same 16 neurons, the mean gustatory response declined by $\sim 14 \%$ during real distension $[F(2,30)=4.00, P<0.03]$; again, there was no effect on spontaneous activity across the three trials $[F(2,30)=1.54$, NS].
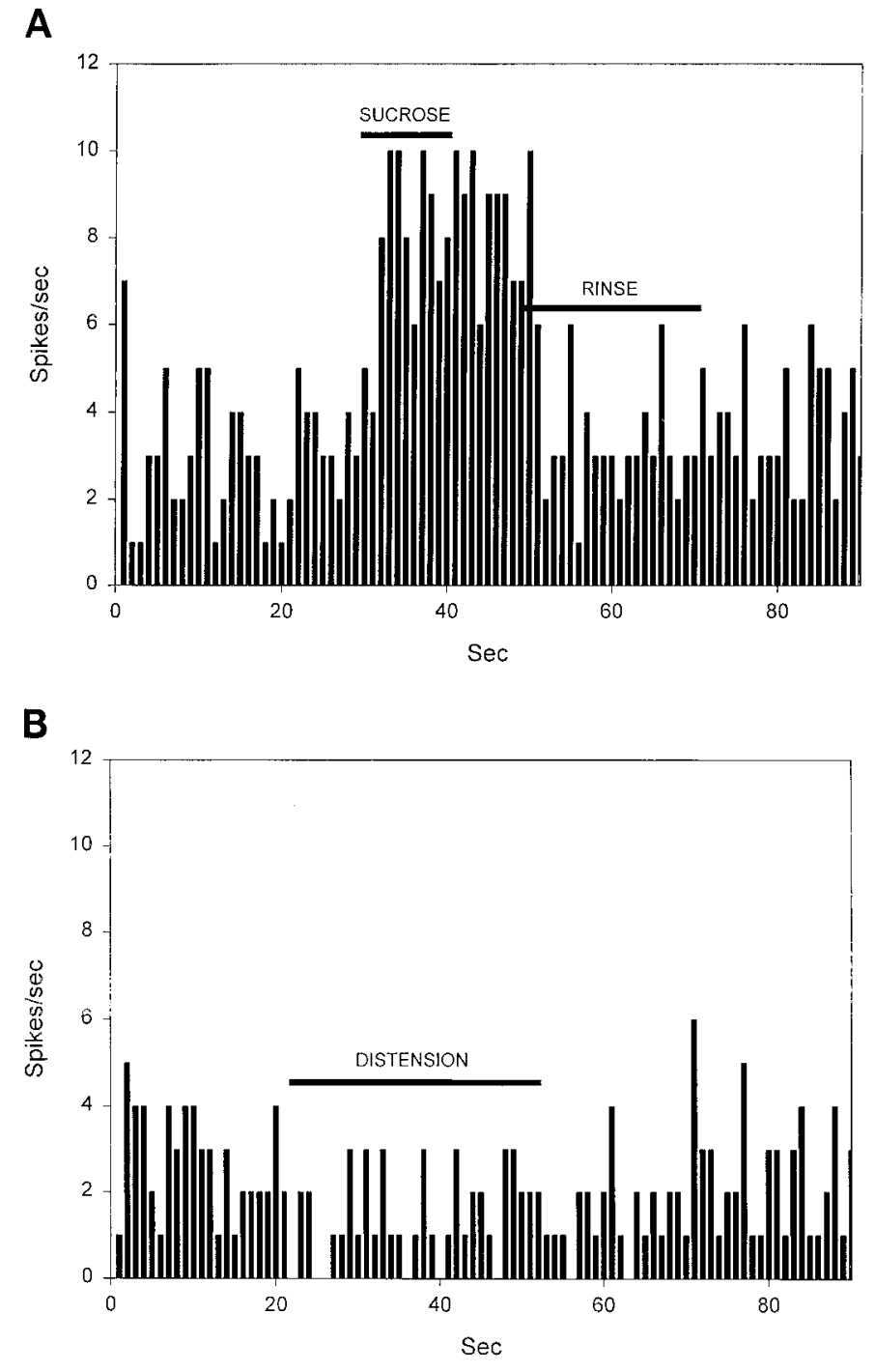

Fig. 1. Example of a coactivated cell. A: cell shows an excitatory response to $0.3 \mathrm{M}$ sucrose application. $B$ : same cell as in $A$ shows an inhibitory response during $12 \mathrm{ml}$ gastric distension.

Although distension effects on taste responsivity across the population were small, some individual cells showed robust effects. When the modulation criterion (see METHODS) was applied to responses obtained from each cell during its best taste response, a suppressive effect of gastric distension was noted in 18/71 (25\%) taste-responsive cells, and a facilitatory effect was noted in $7 / 71$ cells $(10 \%)$. Examples of two neurons showing robust and replicable suppression and enhancement during gastric distension are shown in Fig. 3. Neuron 9906-1 was a sucrose-best neuron that responded to $0.3 \mathrm{M}$ sucrose with a mean net increase of 118 spikes/10 s before gastric stimulation. When the same taste stimulus was applied simultaneously with gastric distension $(18 \mathrm{ml})$, the response declined, on average, to 71 net spikes/10 s and then returned to near baseline levels (122 net spikes/10 s) in the trials after distension. Neuron 9859-3 was a slowly firing neuron that increased its average firing rate by 10 spikes/10 $\mathrm{s}$ in response to its most effective stimulus, 


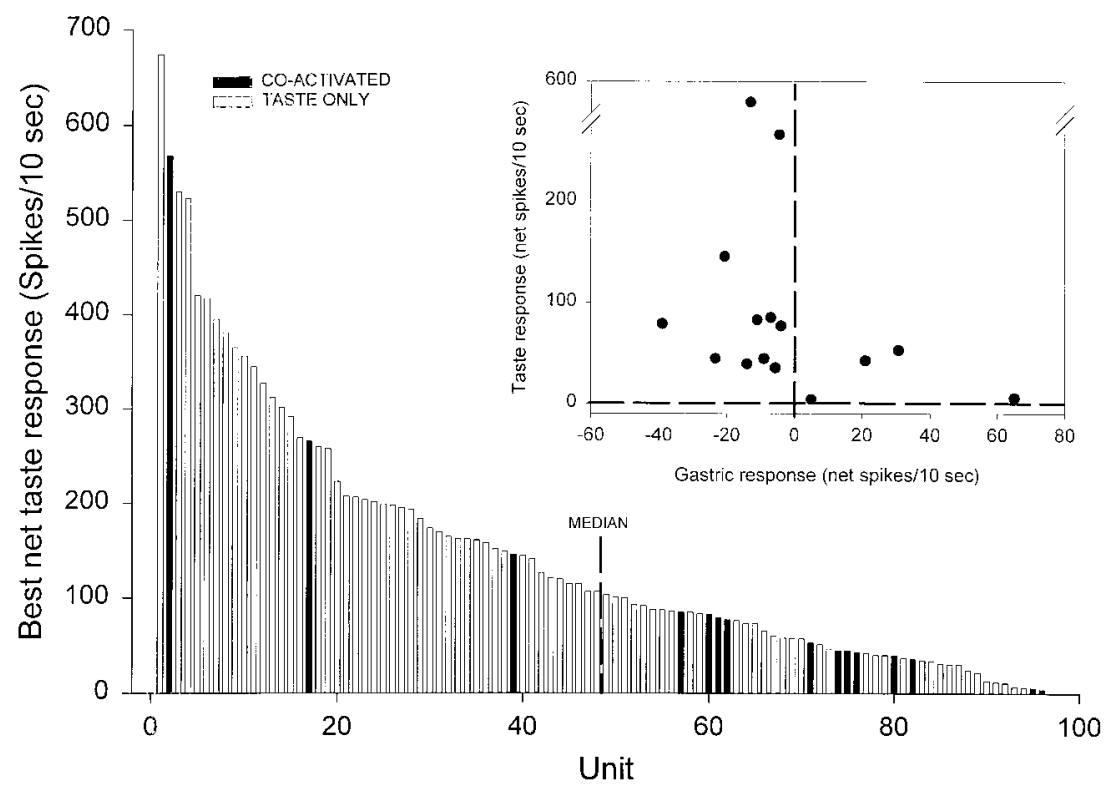

Fig. 2. Rank-ordered distribution of each cell's best net taste response (net spikes/10 s). "Coactivated" cells (filled bars) responded significantly to gastric distension $(n=15)$. Inset: Scatter plot of the magnitude of the best taste response and the gastric distension response (net spikes/10 s) in coactivated cells.

$0.01 \mathrm{M} \mathrm{HCl}$. When the stomach was inflated $(12 \mathrm{ml})$, the mean response tripled to 32 net spikes $/ 10 \mathrm{~s}$ and again returned to baseline in the trials after distension.

Across all neurons meeting inhibitory modulation criteria $(n=18)$, the mean taste response during distension declined by $37 \%$ relative to the average baseline response (Fig. 4A, inset). The suppressive effect was most apparent during the distension period and gradually returned to baseline as the stomach was deflated. For neurons meeting excitatory modulation criteria $(n=7)$, the mean taste response during distension increased by $46 \%$ (Fig. $4 B$, inset). As with the cells showing suppression, the effects of distension on taste were most apparent during the 10-s fully distended period and returned to baseline during deflation.

Thirteen cells meeting modulation criteria were similar to the examples depicted in Fig. 3 in that modulation occurred only during distension. However, in six cells, modulation occurred both during and after distension, and in six cells modulation was seen only after distension. The prolonged influence of distension on taste responses in this subset of cells is apparent in the mean after responses shown in Fig. 4, insets.

The subpopulation of coactivated cells was also evaluated separately for modulation effects (see Table 1). As might be expected in neurons independently responsive to distension, a larger proportion $(7 / 12 ; 58 \%)$ showed modulation compared with those that were not coactivated $(18 / 59 ; 31 \%)$. A two-way $\chi^{2}$ test of this hypothesis was marginally significant $\left[\chi^{2}(1)=3.84\right.$, $P<0.066]$. However, statistical analysis showed no main "before-during-after" effect across the 12 coactivated cells tested for modulation $[F(2,22)=1.69, \mathrm{NS}]$, perhaps because of offsetting excitatory $(n=2)$ and inhibitory $(n=5)$ responses. Nevertheless, there was a positive correlation $(r=0.78, P<0.003$; Fig. 5) between the magnitude and direction of the gastric re- sponse and the magnitude and direction of change in the taste response during the modulation test. Therefore, individual coactivated cells appeared to summate (linearly integrate) their intrinsic taste and gastric response propensities (for both polarity and magnitude) when exposed to conjoint stimulation.

\section{Variations by Taste Quality}

We restricted our analysis of the relationship between gustatory and gastric responsiveness to cells tested with the final stimulus battery $(n=55$; see Table 1). A somewhat detailed description of the chemosensitivity of these neurons is appropriate, since previous investigators have shown that state manipulations modulate taste responses differentially according both to the optimal chemosensitivity of a neuron and its breadth of tuning $(33,43)$. The dendrogram in Fig. 6 shows the results of a cluster analysis, suggesting that the neurons are divisible into four groups, based on responsiveness to $0.3 \mathrm{M}$ sucrose, $0.1 \mathrm{M} \mathrm{NaCl}$, $0.05 \mathrm{M}$ citric acid, $0.1 \mathrm{M} \mathrm{NH}_{4} \mathrm{Cl}$, and $0.003 \mathrm{M} \mathrm{QHCl}$. The groups defined were similar to those reported previously for rodent brain stem taste neurons $(15,33$, $34,44,45)$ and, for the most part, were well defined by their best stimulus. Mean profiles are shown in Fig. 7. The largest group of cells (Fig. $7 C, n=31$, E, or "electrolyte" neurons), was, on average, most responsive to citric acid. However, mean responses of this group to $\mathrm{NaCl}$, and particularly $\mathrm{NH}_{4} \mathrm{Cl}$, were robust (39 and 71\%, respectively), which indicates a general electrolyte sensitivity (Fig. 6). A second group (Fig. 7B, $n=14, \mathrm{~N}$ neurons) was more narrowly tuned. Both on average and for every individual cell, $\mathrm{N}$ neurons responded best to $\mathrm{NaCl}$ (Fig. 6). The second-best stimulus was $\mathrm{NH}_{4} \mathrm{Cl}$, which evoked a mean response only $38 \%$ as great as NaCl. A third group (Fig. 7A, S neurons, $n=8$ ) was characterized by an enhanced sucrose responsiveness. Sucrose nominally elicited the largest 
A

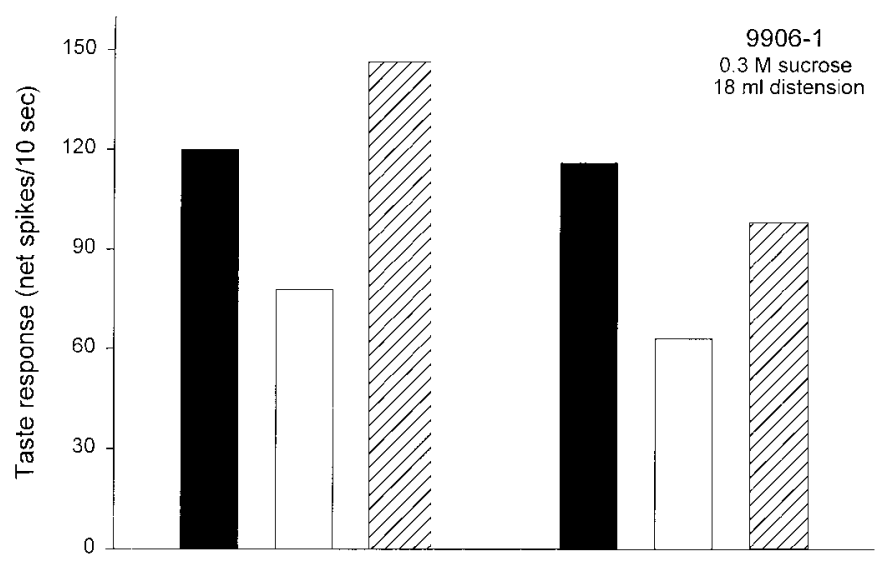

Trial 1

Trial 2

$\mathbf{B}$

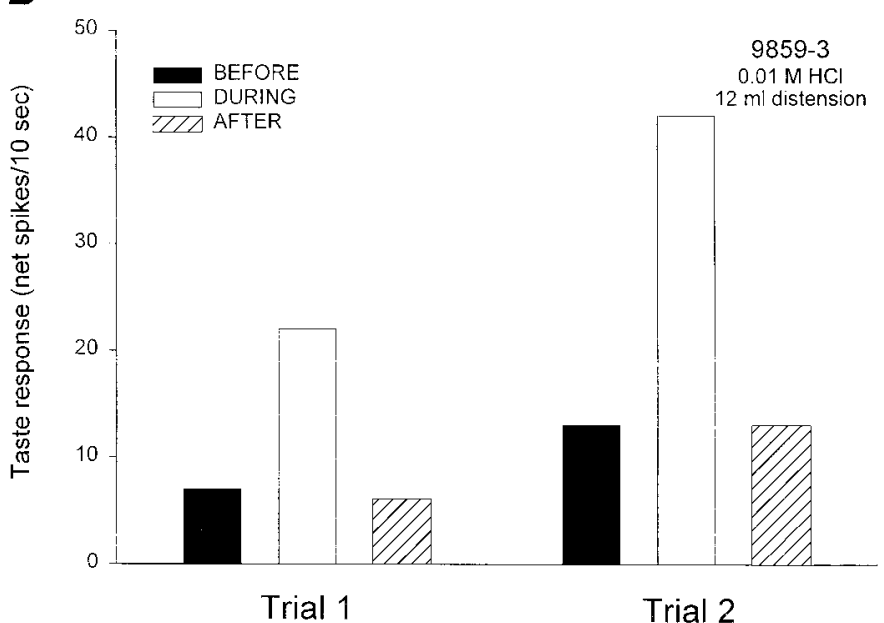

Fig. 3. Individual examples of modulation. A: consecutive modulation tests for a sucrose-best cell that was suppressed during $18 \mathrm{ml}$ gastric distension and returned to baseline after distension. B: consecutive modulation tests for an $\mathrm{HCl}$-best neuron that was excited during $12 \mathrm{ml}$ gastric distension. Filled bars, taste response before distension; open bars, taste response during distension; hatched bars, taste response after distension. Taste stimulation in the during conditions corresponded to the 10 -s period of full distension (see Fig. 4).

mean response in $\mathrm{S}$ neurons, but the response to the second-best stimulus, $\mathrm{NH}_{4} \mathrm{Cl}$, was $82 \%$ as great. Indeed, only $5 / 8 \mathrm{~S}$ neurons actually responded best to sucrose (Fig. 6). The final two neurons formed a small "group" most responsive to $\mathrm{QHCl}$ (Fig. 7D). However, the mean response to $\mathrm{QHCl}$ for this group was small relative to the optimal responses for the other groups of cells, and the response to $\mathrm{NH}_{4} \mathrm{Cl}$ was relatively large.

Similar to what was observed across the entire population, $14 \%$ of the cells tested with the final stimulus battery were coactivated. Coactivated neurons appeared evenly distributed across clusters. Two of $14 \mathrm{~N}$ cluster cells (14\%), 4/31 E cluster cells (13\%), 1/8 S cluster (13\%) cells, and 1/2 quinine cluster cells were coactivated.
In contrast, there was evidence for a relationship between gustatory chemosensitivity and modulation. Thirty-eight of the 55 cells tested with the final stimulus battery ( $7 \mathrm{~S}, 11 \mathrm{~N}, 18 \mathrm{E}$, and $2 \mathrm{Q}$ ) were available for the modulation analysis, i.e., those tested for modulation of their cluster-best tastant by gastric stimulation with the highest volume tested for an individual cell. For ANOVA tests, the $\mathrm{QHCl}$ cells were removed because of the small sample size, leaving three factors (taste clusters) in the quality dimension. Across this sample, two-way ANOVA revealed no systematic effect of distension according to cluster type [cluster: $F(2,33)=0.47$, NS; interaction: $F(4,66)=0.53, \mathrm{NS}]$. However, as for the entire population of cells, there was a main inhibitory effect of distension $[F(2,66)=$ $3.32, P<0.04]$. For individual responses, $2 / 7 \mathrm{~S}, 6 / 18 \mathrm{E}$, $2 / 2 \mathrm{Q}$, but only $1 / 11 \mathrm{~N}$ cells showed a modulation that satisfied the criterion (see Table 2). $\chi^{2}$ tests indicated that the $\mathrm{N}$ neurons were less likely to be modulated than the other types of cells $\left[\chi^{2}(1)=7.37, P<0.007\right]$. With respect to response direction, two of the six modulated acid-cluster cells showed excitatory modulation; all other cells showed inhibitory modulation.

Because Hajnal et al. (33) showed that the breadth of gustatory tuning was related to the magnitude of modulation, we correlated entropy to the magnitude of modulation (percentage of baseline), but no significant relationship $(r=-0.19$, NS) was observed. We also compared the breadth of tuning of cells that were or were not modulated, but the difference was not significant $[F(1,50)=2.78, P<0.10]$.

\section{Topography-Integration Relationships}

The majority of histologically identified units (29/31) was located in the caudal half of the PBN (Fig. 8A, levels $a$ and $b$ ). Most cells were recorded within the brachium itself, both ventral and lateral to the ventral lateral subnucleus, where a subset of cells $(n=5)$ was also localized. Several cells were located in the central medial subnucleus, ventral to the brachium. Taste cells that exhibited gastric responsivity (coactivation and/or modulation) were not uniquely distributed in the PBN compared with taste cells with no evidence of gastric input $\left[\chi^{2}(2)=1.83, \mathrm{NS}\right]$. However, compared with cells that responded only to gastric distension (replotted from Ref. 4; Fig. 8B), a greater proportion of gastric cells was located in the rostral levels of PBN than were taste cells $\left[\chi^{2}(3)=17.92, P<0.0001\right]$. Despite this statistical segregation, there was considerable overlap between gastric-only and taste-responsive cells in the caudal taste areas. Moreover, taste-responsive cells that were also gastric responsive were comingled with taste-specific neurons in the caudal PBN (Fig. 8A).

\section{DISCUSSION}

Approximately one-third of the gustatory cells tested were either coactivated or modulated by gastric distension. These data provide evidence of taste-visceral integration in the PBN using naturalistic stimuli and complement previous studies that implicate this nu- 
A

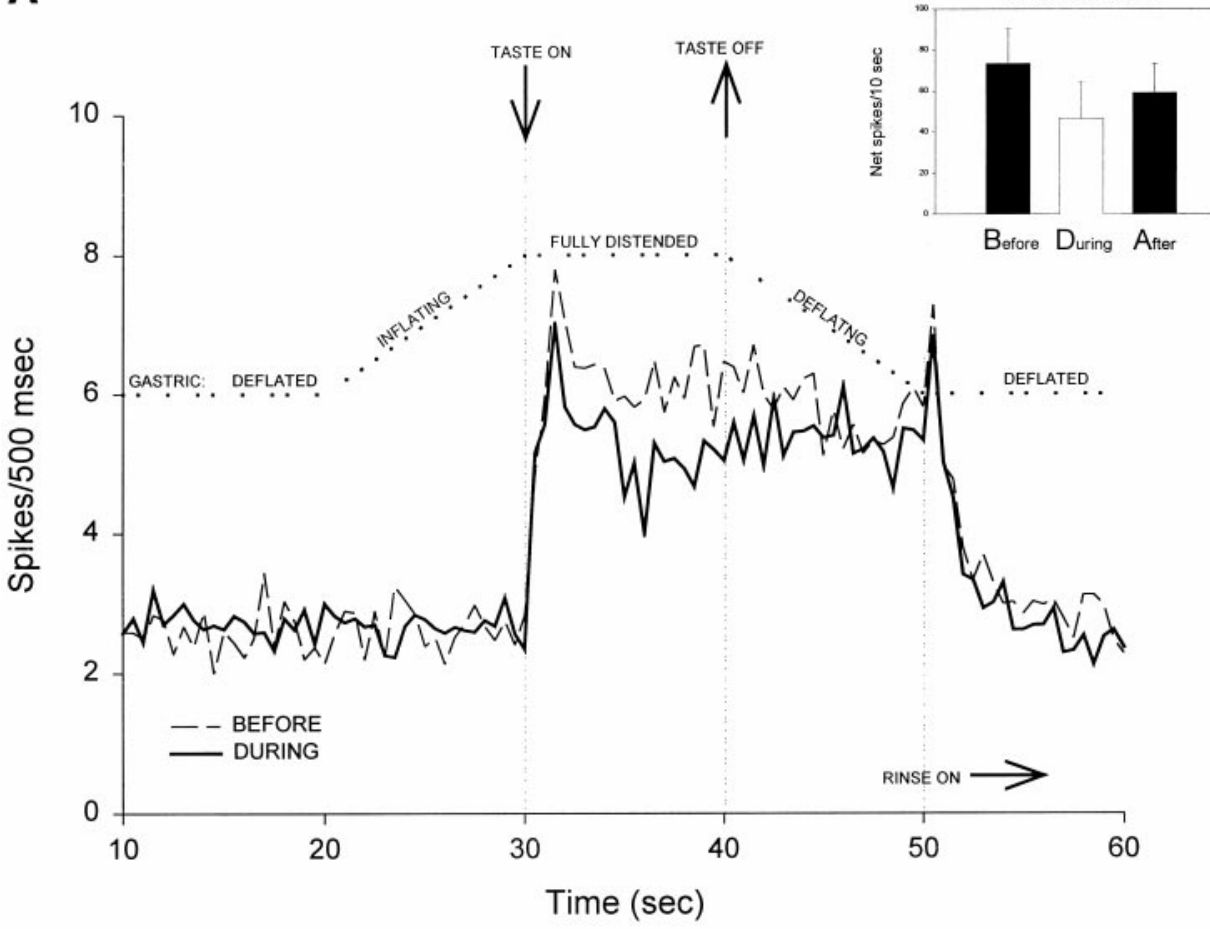

Fig. 4. Modulation effect for cells satisfying the $25 \%$ criterion. $A$ : mean time course response of 18 inhibitory cells to taste stimulation before and during gastric distension. Inset: mean + SE net response of 18 cells to taste stimulation before, during (middle $10 \mathrm{~s}$ of distension), and after gastric distension. The decline in gustatory response during distension in these 18 cells averaged $37 \%$ suppression from base-

B

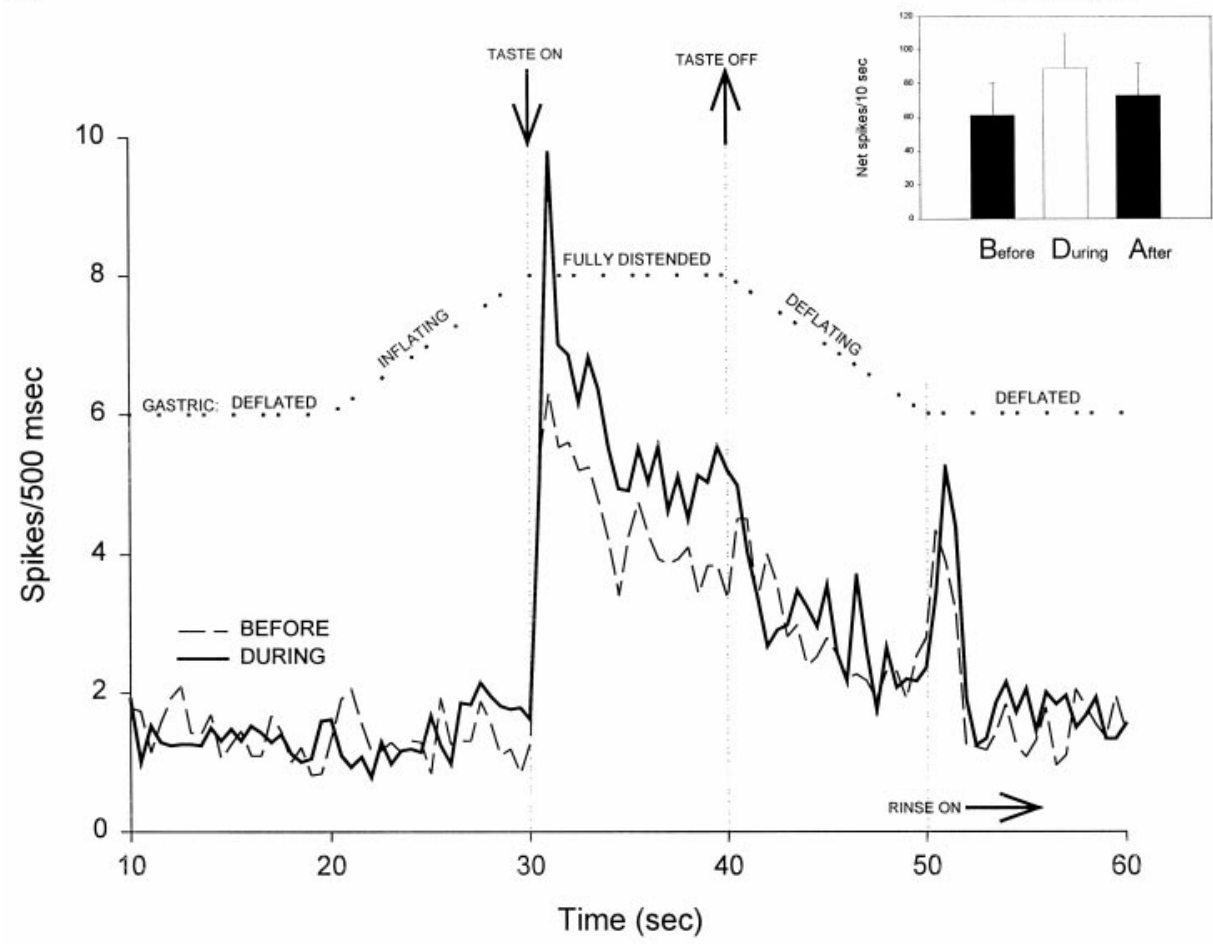
line. $B$ : mean time course response of 7 excitatory cells to taste stimulation before and during gastric distension. Inset: mean $+\mathrm{SE}$ response of cells during taste stimulation before, during (middle $10 \mathrm{~s}$ of distension), and after gastric distension. The excitatory taste response during distension averaged $46 \%$ above baseline. cleus as an important locus for the coordination of the afferent taste and visceral signals that structure feeding (e.g., Refs. 29, 33, 36, 40, 41, 50, 52, 56).

\section{Inhibitory Effects of Distension}

Overall, gastric distension had an inhibitory effect on taste-responsive cells. However, rather few taste cells (16\%) responded outright to gastric stimulation. This is notably smaller than the proportion of gustatory neurons coactivated by electrical stimulation of the cervical vagus and tongue (54\%; see Ref. 36). The larger proportion of gustatory cells coactivated by vagal stimulation is not surprising, because this stimulus would be likely to evoke a simultaneous barrage of 


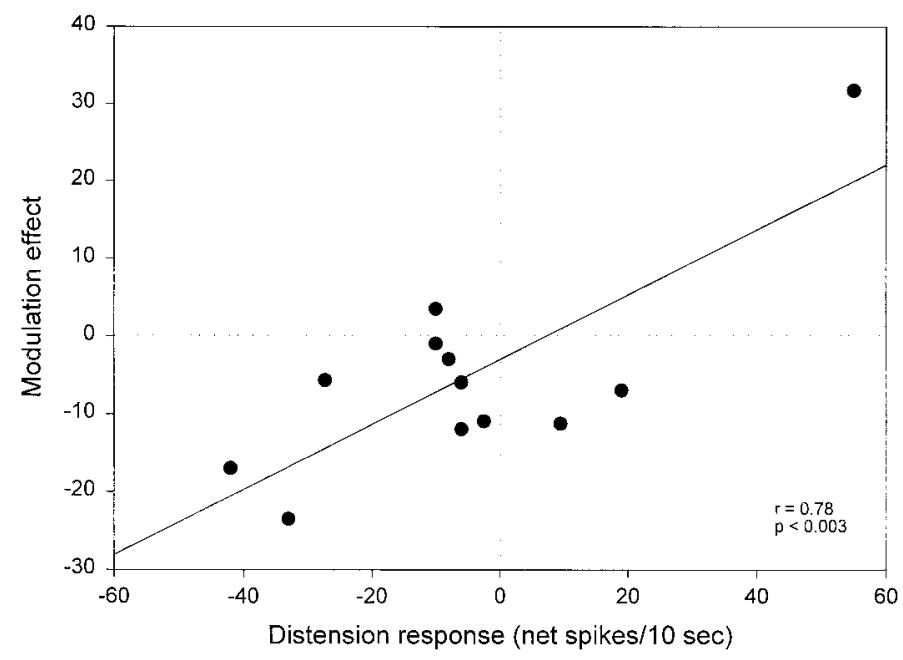

Fig. 5. Response of coactivated cells to conjoint taste and gastric stimulation. There was a significant correlation between the net magnitude of the gastric distension response (net spikes/10 s) and the change in the taste response (net spikes/10 s) during distension vs. baseline tests $(r=0.78, P<0.003)$. In all but three cases, the direction of change in the taste response during conjoint stimulation was in the same direction as the gastric response.

activity from many types of visceral afferent fibers in addition to gastric mechanoreceptors. As a group, taste responses of coactivated gustatory neurons in the present study were weak compared with the overall population (Fig. 2). Their distension responses were even smaller, although generally consistent with the magnitude of distension responses reported in the PBN $(4,58)$. However, their inhibitory nature distinguishes them from PBN gastric-responsive cells with no taste sensitivity, which are usually excitatory $(4,58)$. The inhibitory character of the present distension responses is emphasized by the overall suppressive effect seen during conjoint stimulation (modulation). Indeed, responses to distension were more commonly in the form of modulation, which was observed about two times as often as coactivation (35\% modulated vs. $16 \%$ coactivated).

Although pervasive, the magnitude of inhibition and its association with specific gustatory responses differed from previous studies. Intestinal intralipid infusions depressed overall average gustatory responsiveness in the PBN by $16 \%$ compared with $6 \%$ in the present study (33). Similarly, intralipid infusion and other treatments intended to mimic or produce satiety, including intravenous glucose, glucagon, or insulin injections, all suppressed central gustatory responses to carbohydrates by $\sim 30-50 \%(20,21,23,24,26,33)$, compared with only $10 \%$ for the sucrose group in the present study. In addition, previous investigations reported that responses to palatable tastants (especially carbohydrates but sometimes $\mathrm{NaCl}$ ) showed more prominent inhibitory modulation after peripheral treatment compared with responses to unpalatable stimuli, like acids or quinine (20, 21, 23, 24, 26, 33). Although the suppression we observed was significantly underrepresented in $\mathrm{NaCl}$-best neurons, it was otherwise apparent in all best-stimulus classes, i.e., those representing both appetitive and aversive taste stimuli.

In evaluating why our inhibitory effect was weaker, it is important to point out that a subset of the cells $(25 \%)$ in the present investigation did show stronger $(>25 \%)$ inhibitory modulation. In addition, a few taste responses were actually facilitated $(>25 \%)$ by distension. An enhancement of taste responses by satiating stimuli has not been reported previously (20-24, 26 , 33 , and cf. Ref. 36), and their countervailing influences may partially account for the modest average decline. However, other variables are probably more important.

Assuming that suppression of PBN gustatory responses is a mechanism for producing satiation, we may speculate that the weaker effects of gastric distension on PBN gustatory responsiveness parallel a weaker potency of gastric distension to suppress feeding compared with caloric stimuli. In rats with closed pyloric cuffs, distension produced by intragastric saline loads of $5-10 \mathrm{ml}$ (100-200\% of baseline intake) suppressed intake by $30-70 \%$ of baseline (49). These volumes fall within the range of those tested here, where a mean suppressive effect on PBN taste responses of

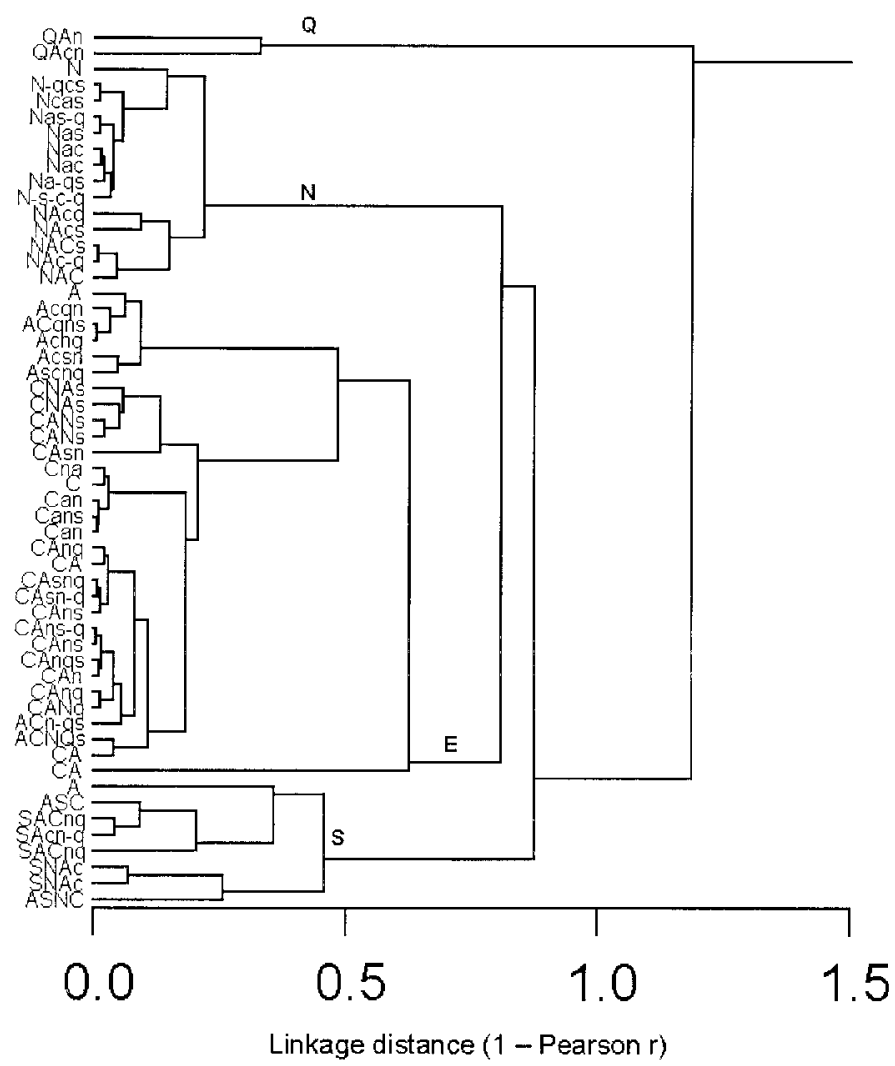

Fig. 6. Cluster tree of 55 taste-responsive cells. Cells are labeled according to significant responses in order of magnitude. The first letter indicates the tastant that evoked the best response. Capital letters indicate that the response was at least $50 \%$ as great as that elicited by the best stimulus. A dash preceding a letter indicates that there was an inhibitory response to this tastant. $\mathrm{A}, \mathrm{NH}_{4} \mathrm{Cl} ; \mathrm{C}$, citric acid; $\mathrm{N}, \mathrm{NaCl} ; \mathrm{Q}, \mathrm{QHCl} ; \mathrm{S}$, sucrose. Cells generally most responsive to $\mathrm{A}$ and $\mathrm{C}$ fell under one cluster, termed " $\mathrm{E}$ ", which reflected a common electrolyte sensitivity cluster (see text for details). 
A

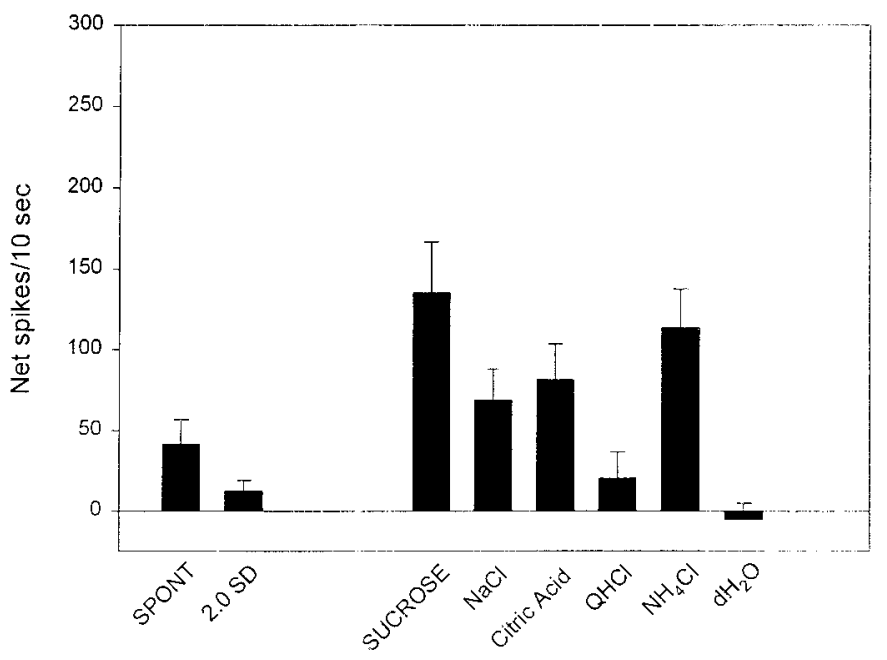

C

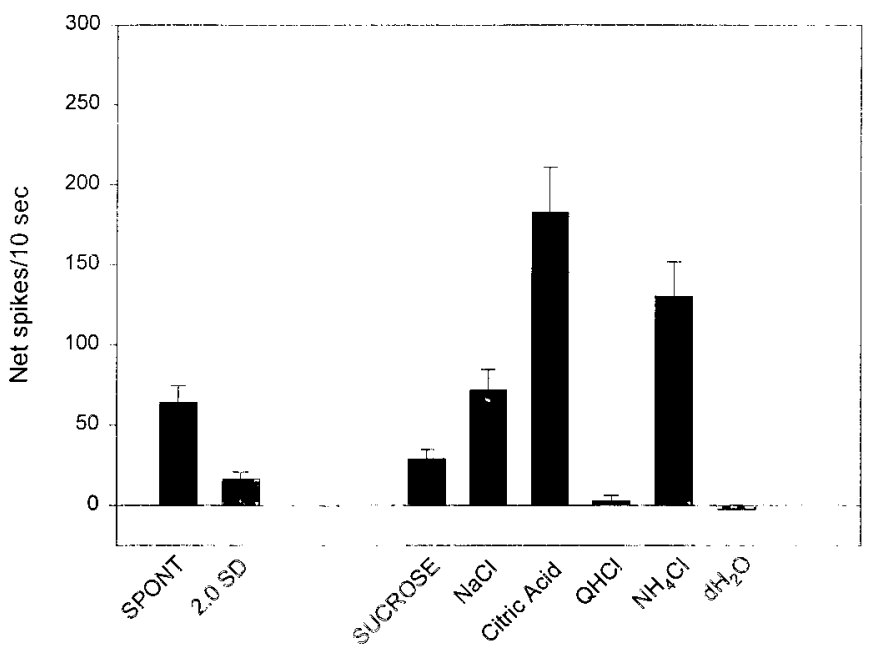

B

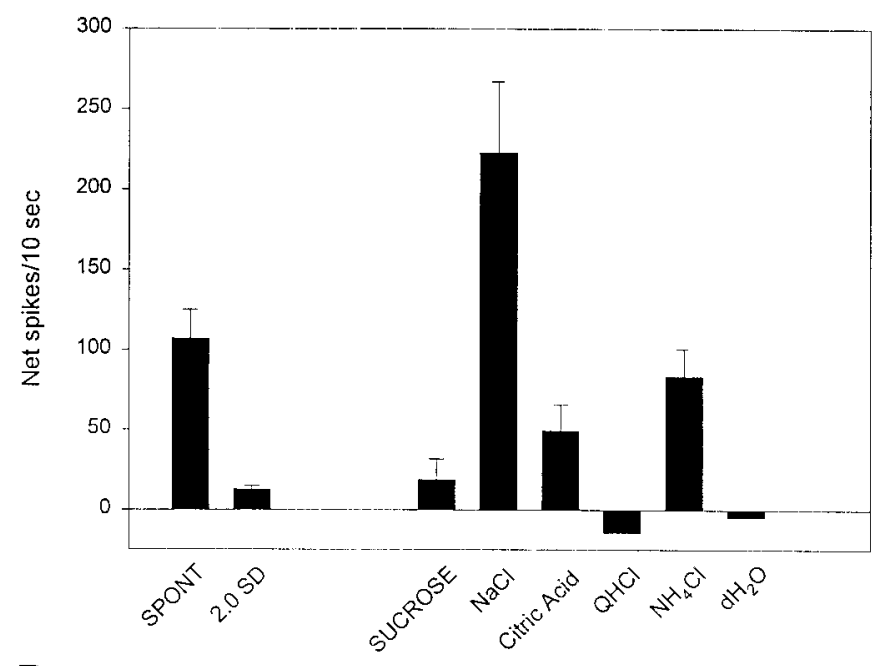

D

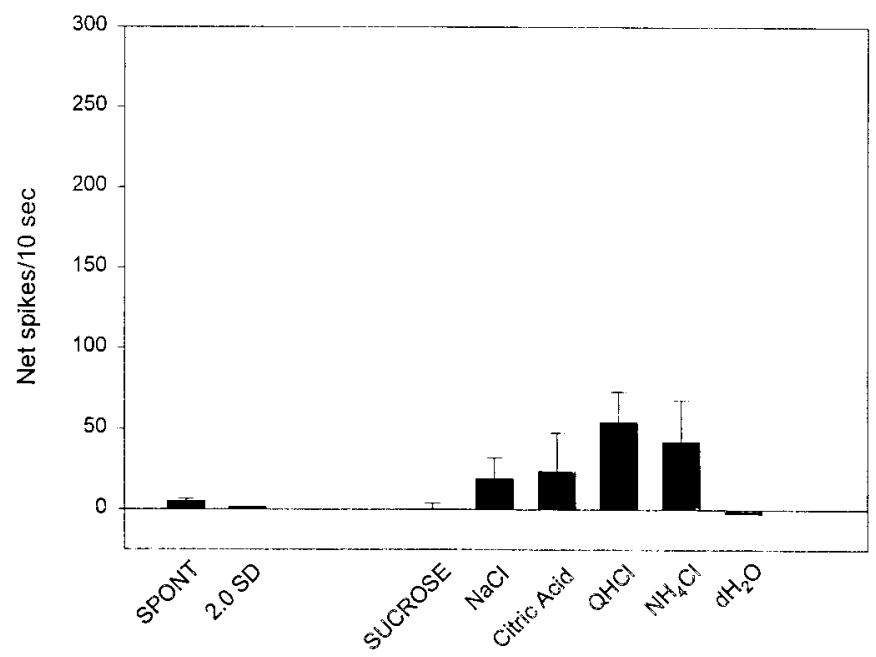

Fig. 7. Mean response profiles for each of the 4 taste clusters. $A$ : sucrose cluster. $B$ : NaCl cluster. $C$ : citric acid cluster. D: QHCl cluster. Spont, spontaneous.

$6 \%$ was observed. By contrast, the same intralipid infusions that decreased PBN sucrose responses by $30 \%$ almost completely abated sucrose ingestion for many minutes (see Fig. 2 in Ref. 18). It is difficult, however, to separate the individual contributions of distension and calories across gastrointestinal compartments, independent of other hormonal, metabolic, and mechanical consequences of a postingestive stimulation.

Table 2. Modulation by cluster quality

\begin{tabular}{lccr}
\hline \hline Cluster Type & Modulated & Not Modulated & Total \\
\hline $\mathrm{NaCl}$ & $1(9)$ & $10(91)$ & 11 \\
Sucrose & $2(28)$ & $5(72)$ & 7 \\
Citric acid & $6(33)$ & $12(66)$ & 18 \\
QHCl & $2(100)$ & $0(0)$ & 2 \\
Total & 11 & 27 & 38 \\
\hline
\end{tabular}

No. and proportion of cells in each taste cluster that did or did not show a significant change $(>25 \%$ baseline) in taste response during gastric distension. Percentages are in parentheses.
It is equally difficult to compare the behavioral efficacy of different treatments against what occurs during normal digestion. When compartments of peripheral feedback are isolated and stimulated out of the context of normal digestion [e.g., the liver (3) or stomach distension (see above)], the inhibitory influences on intake are smaller compared with the effects of oral, gastric, or even intestinal nutrient preloads (e.g., Refs. 39 and 55). Thus stimulation of any single visceral compartment is likely to only partially reveal the capability of such stimuli to influence satiation mechanisms. Perhaps gastric distension initiates a process of gustatory response suppression that is accentuated over time if the gastric load is caloric and reaches the small intestine (see Ref. 55).

Another important variable to consider is the duration of the visceral stimulus. The duration of our visceral treatment (30 s) was much shorter than previous studies, and the metabolic load treatments used in the past likely had long-term influences (at least) tens of 
Fig. 8. Schematic representation of the locations of neurons recorded in the parabrachial nucleus (PBN). Serial sections are arranged caudal (a) to ros$\operatorname{tral}(d), \sim 200 \mu \mathrm{m}$ apart. $A$ : distribution of taste neurons with no gastric sensitivity $(\bigcirc)$ and taste neurons that were either independently responsive to distension (coactivated; $\bullet$ ) or showed taste modulation during distension but no intrinsic distension response per se ( $\mathbf{\square}$; see text for details). Only lesions made immediately after cell testing, without moving the electrode, were plotted. $B$ : comparison of loci of taste cells (all types; $\triangle$ ) and gastric distension-responsive cells that had no taste sensitivity (*; replotted from Ref. 4). Gastric cells with lesions made at the recording site are plotted as symbols without accompanying tracks. Gastric cells with lesions made within $250 \mu \mathrm{m}$ of the recording site are denoted by symbols nominally placed at the top of the track. Tracks with two symbols indicate that two cells were found on the track. bc, Brachium conjuctivum; cl, central lateral subnucleus; dl, dorsal lateral subnucleus; el, external lateral subnucleus; em, external medial subnucleus; il, internal lateral subnucleus; LC, locus ceruleus; Me5, mesencephalic trigeminal nucleus; sl, superior lateral subnucleus; vl, ventral lateral subnucleus; Mo5, motor trigeminal nucleus; Pr5, primary sensory trigeminal nucleus; vsc, ventral spinocerebellar tract; cm, central medial.
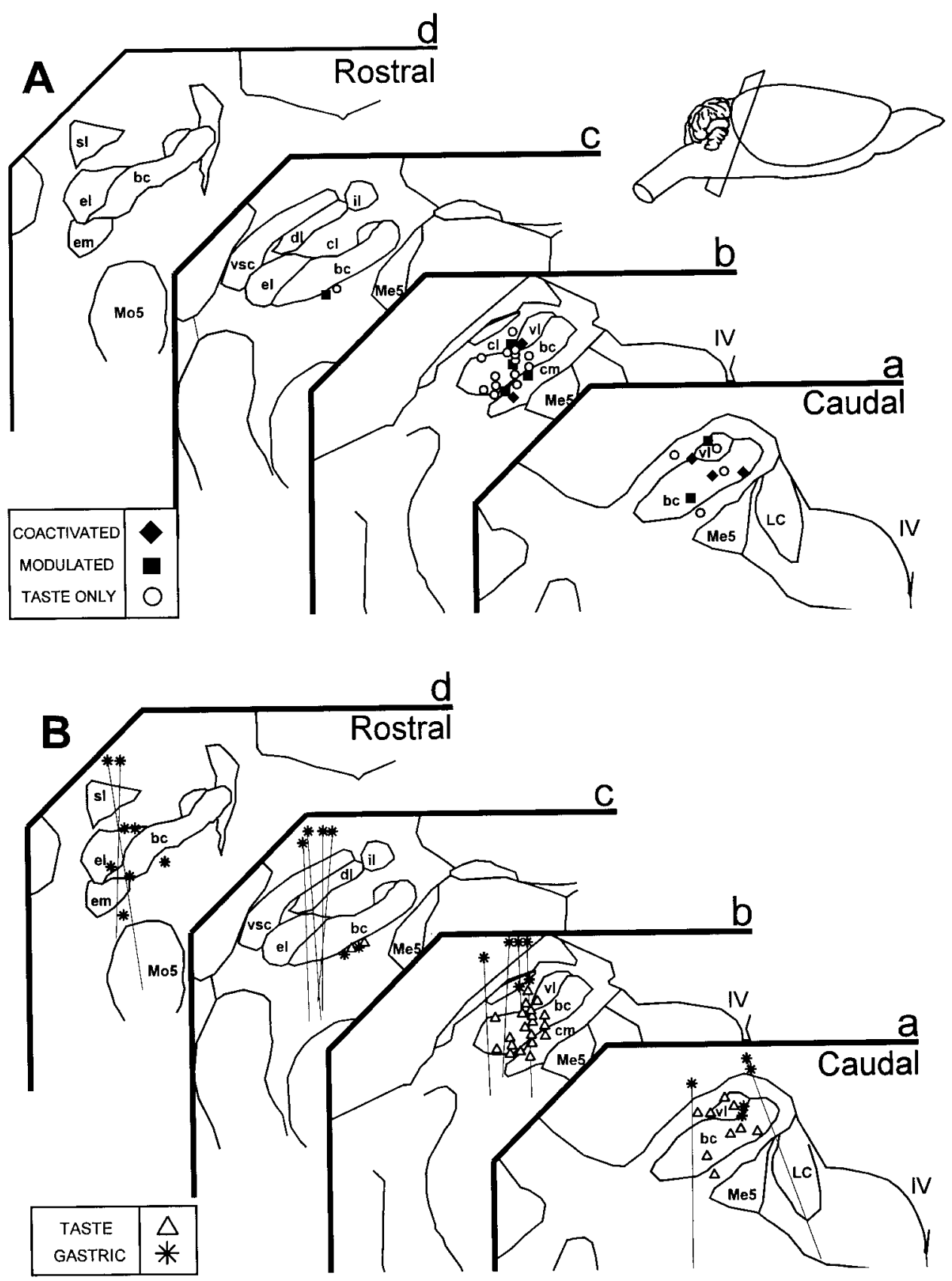

minutes long. Indeed, although an effect of intralipid stimulation on taste responses could be discerned $\sim 2$ min after infusion, it was very small compared with the maximum suppression observed $\sim 10$ min postinfusion (33). Although the relatively short latency argues for a preabsorptive action of intralipid infusion (33), the minutes-long delay before maximum efficacy suggests that intestinal modulation of taste responses may be more complex than a simple integration of intestinal inhibitory and gustatory excitatory signals. Further evidence for a more complicated mechanism by which visceral feedback modifies taste responses is evident in the classic study of Glenn and Erickson (26), which, like ours, used noncaloric gastric distension. These investigators found that NST multiunit sucrose responses were suppressed $\sim 50 \%$ during gastric distension. However, they used a prolonged distension period ( $\sim 15 \mathrm{~min})$. Inspection of their Fig. 1 and our own review of their raw data (obtained from Ref. 25) suggests that an early effect of distension (i.e., within $60 \mathrm{~s}$ of inflation) was not evident. Rather, the response suppression was, as they stated, “. . .slowly developing (several minutes)..." (26), reaching a nadir by about the 6th min. These findings suggest that more potent modulations of taste responses by postingestive signals may require some time-dependent process, such as hormone secretion, metabolic cascades, or prolonged neuromodulator release in the central nervous system (e.g., Refs. 3, 48, and 53).

In addition to their smaller magnitude, the modulatory effects in the present study were less specific than 
in previous studies. Previous studies of the modulation of brain stem taste responses by satiety-mimicking manipulations have reported preferential effects on carbohydrate (glucose or sucrose)-elicited responses $(20,21,23,24,26,33)$. We only partially corroborated this finding. Sucrose responses were modulated more frequently than $\mathrm{NaCl}$ responses. However, they were no more susceptible to the effects of gastric distension than were citric acid responses. The reason for the lack of a more specific effect on sucrose responses is not obvious, but it may relate to properties of the sucrosesensitive (S cluster) neurons we recorded. Specifically, in the only other single-unit study of brain stem visceral-gustatory modulation, sucrose responses were suppressed only in cells that responded best to this stimulus (33). Moreover, the largest modulations occurred in neurons specifically responsive to this stimulus, i.e., they were narrowly tuned cells with no response to any other class of tastant. By comparison, neurons in the sucrose-sensitive cluster of the present study were broadly responsive and only nominally sucrose best (Fig. 7A).

The lack of effect of gastric distension on the $\mathrm{NaCl}$ responses we observed is not incompatible with previous findings. Multiunit studies using intravenous glucose, insulin, and glucagon likewise noted that NST $\mathrm{NaCl}$ responses were unaffected by these treatments $(20,21,23,24)$. In addition, $\mathrm{PBN} \mathrm{NaCl}$ responses were suppressed by intestinal lipid but less so than sugar responses. In fact, modulation of salt responses only occurred in broadly tuned NaCl-best cells. NaCl-specific cells were not affected. Although all of the NaClbest cells in the present study displayed some response to other stimuli, as a class, they were the most narrowly tuned group.

The modulation of PBN acid responses by gastric distension in the present study starkly contrasts past studies where neither intravenous satiety factors nor gastric distension appeared to modulate similar taste responses in the NST $(20,21,23,24,26)$. Intestinal intralipid also did not affect citric acid responses in the PBN, although a very small sample of acid-best cells $(n=4 / 59)$ was recorded in that study (33). Because all other instances of intestinal intralipid modulation for a given taste quality were confined to the subgroup of cells optimally responsive to that tastant, it is possible that the small sample of acid-best neurons obscured such an effect. It may be noteworthy that the only excitatory modulations we observed were from the acid cluster. Conceivably, if a larger proportion of acid cells showed excitatory responses than other cluster groups, it could account for the lack of an inhibitory effect in previous multiunit studies.

\section{Mechanisms of Integration}

The brief latency with which gastric effects occurred in PBN taste neurons suggests that they were mediated via gastric afferent pathways rather than indirect hormonal means. Previous studies suggest a simple anatomical substrate for taste-visceral integration in
PBN with pontine neurons innervated by separate populations of NST cells responsive to gustatory and gastric stimulation, respectively. This hypothesis received early support when Hermann and colleagues (37) demonstrated a lack of oral-vagal convergence in the NST, whereas PBN neurons were coactivated by both signals, with short latencies consistent with a direct medullary projection (36). Although electron microscopic data are necessary to confirm monosynaptic convergence, light microscopic analysis demonstrated intermingling of NST gastric and taste projections in the PBN waist region (40). On the other hand, there is no paucity of anatomical evidence for more complex taste-visceral circuits, including local PBN connections and descending forebrain projections (51).

The present study was not designed to define cellular mechanisms, but the nature of PBN taste-gastric integration provides clues to their general nature. Integration in taste neurons was most often evident only because the gustatory response was modified (modulated) by gastric stimulation; gastric stimulation itself did not elicit a response. Hajnal et al. (33) made a similar observation. Duodenal nutrient infusions had no effect on spontaneous rates of PBN taste cells, even though they profoundly inhibited gustatory responses. These observations imply that gastrointestinal modification of taste responses may result from presynaptic inhibition or from a chemical messenger acting as a neuromodulator (38). The PBN is replete with transmitters and receptors with neuromodulatory actions, including peptidergic and monoaminergic fibers (e.g., Refs. 7, 35, and 42), and a host of metabotropic receptors (e.g., Refs. 9, 10, and 31). In fact, several populations of peptidergic NST-PBN projection neurons originate in the caudal, visceral NST (35). However, in addition to neurons whose taste response was only modified by gastric stimulation, we observed another, smaller population of cells coactivated by gastric stimulation. For these cells, there was a significant correlation between the magnitude of the gastric response and the degree to which gastric stimulation modified the taste response. The linear integration in these neurons is more suggestive of simple spatial summation mediated by classic neurotransmitters and ionotropic receptors (38).

\section{Topography of Taste and Distension Responses}

It is significant that both modulated and coactivated taste cells extended to the most caudal reaches of the PBN (Fig. 8A), areas not traditionally associated with visceral sensitivity (e.g., Ref. 52). Coactivated cells intermingled with a substantial population of neurons purely responsive to taste stimulation and a smaller number responsive only to gastric stimulation. These observations emphasize that there is not a strict morphological division of the PBN into gustatory and visceral zones. However, this is not to suggest a lack of topographic organization. Indeed, there was a differential distribution of gastric- and taste-responsive cells, a distribution consistent with previous anatomical stud- 
ies and classical descriptions of taste vs. visceral regions in the PBN $(35,40,46)$. Taste-responsive neurons were distributed in the caudal waist region, spanning the brachium conjunctivum between the ventral lateral and central medial subnuclei. By comparison, gastric-responsive cells were preferentially distributed further anteriorly and laterally, with many located in or near the external lateral subnucleus. One caveat should be noted. In the present study, we recorded no gustatory neurons in the external subnuclei, an area where a small population of taste neurons was previously identified (34). The reason for this discrepancy is unclear. However, the "external" taste neurons observed previously were all responsive to posterior mouth stimulation. Although the whole mouth was stimulated in the present study, receptive fields were not determined, and we may not have recorded a representative sample of such neurons (e.g., Ref. 34). Thus the distribution of taste- and gastric-responsive neurons may be even more overlapping than that observed here.

\section{Perspectives}

An inhibitory influence of gastric distension on excitatory taste responses is consistent with a role for distension as an inhibitory feedback signal that enhances satiation and diminishes ingestive taste reactivity $(8,13,32)$. More generally, the inhibitory distension effect can be taken on face value to support the model of feeding behavior proposed by Davis and Levine (13). In simple terms, the model states that feeding behavior varies as a function of the integration of excitatory afferent signals derived from palatable gustatory stimuli and inhibitory afferent signals derived from postingestive accumulation of ingesta. It is noteworthy, however, that inhibitory modulation was not confined to palatable stimuli in the present study. It is not immediately obvious how inhibition of aversive taste responses should be interpreted in behavioral terms. On the one hand, it could be argued that there is no clear role for gastric modulation of aversive gustatory signals, based on the assumption that aversive tastants are not ordinarily ingested. However, natural foods are complex mixtures that contain both aversive and palatable components. For example, carbohydrates are often present in combination with acids in fruit. Thus a general suppression of palatable and aversive gustatory input by satiating factors could be adaptive in certain contexts (also see Ref. 28). Indeed, one early study showed that intraperitoneal cholecystokinin injections suppressed intake of hypertonic saline and quinine in addition to glucose (5), but, for the most part, relatively little is known about how satiating treatments affect the hedonic evaluation and consumption of tastants other than carbohydrates (28).

We thank Hamid Karimnamazi, Mark Dinkins, and Kevin Urbanek for instruction, assistance, and advice.

This research was supported by National Institute for Deafness and Other Communicative Disorders Grants DC-00382 to J.-P. Baird, DC-00416 to S. P. Travers, and DC-00417 to J. B. Travers.

\section{REFERENCES}

1. Adachi A. Projection of the hepatic vagal nerve in the medulla oblongata. J Autonom Nerv Sys 10: 287-293, 1984.

2. Appia F, Ewart WR, Pittam BS, and Wingate DL. Convergence of sensory information from abdominal viscera in the rat brain stem. Am J Physiol Gastrointest Liver Physiol 251: G169G175, 1986.

3. Baird J-P, Grill HJ, and Kaplan JM. Intake suppression after hepatic portal glucose infusion: all-or-none effect and its temporal threshold. Am J Physiol Regulatory Integrative Comp Physiol 272: R1454-R1460, 1997.

4. Baird J-P, Travers JB, and Travers SP. Parametric analysis of gastric distension responses in the parabrachial nucleus. Am $J$ Physiol Regulatory Integrative Comp Physiol 281: R1568-R1580, 2001.

5. Bartness TJ and Waldbillig RJ. Cholecystokinin-induced suppression of feeding: an evaluation of the generality of gustatorycholecystokinin interactions. Physiol Beh 32: 409-415, 1984.

6. Berthoud HR, Carlson NR, and Powley TL. Topography of efferent vagal innervation of the rat gastrointestinal tract. Am $J$ Physiol Regulatory Integrative Comp Physiol 260: R200-R207, 1991.

7. Block CH and Hoffman GE. Neuropeptide and monoamine components of the parabrachial pontine complex. Peptides 8: 267-283, 1987.

8. Cabanac $M$ and Lafrance $L$. Ingestive/aversive response of rats to sweet stimuli. Influence of glucose, oil, and casein hydrolyzate gastric loads. Physiol Behav 51: 139-143, 1992.

9. Chamberlin NL, Mansour A, Watson SJ, and Saper CB. Localization of mu-opioid receptors on amygdaloid projection neurons in the parabrachial nucleus of the rat. Brain Res 827: 198-204, 1999.

10. Chen X, Zidichouski JA, Harris KH, and Jhamandas JH. Synaptic actions of neuropeptide FF in the rat parabrachial nucleus: Interactions with opioid receptors. $J$ Neuorphysiol 84: 744-751, 2000.

11. Davis JD. The microstructure of ingestive behavior. Ann NY Acad Sci 575: 106-121, 1989.

12. Davis JD, Collins BJ, and Levine MW. Peripheral control of drinking: gastrointestinal filling as a negative feedback signal, a theoretical and experimental analysis. J Comp Physiol Psychol 89: $985-1002,1975$.

13. Davis JD and Levine MW. A model for the control of ingestion. Psychol Rev 84: 379-412, 1977.

14. Davis JD and Smith GP. Analysis of the microstructure of the rhythmic tongue movements of rats ingesting maltose and sucrose solutions. Behav Neurosci 106: 217-228, 1992.

15. Dinkins ME and Travers SP. Altered taste responses in adult NST after neonatal chorda tympani denervation. J Neurophysiol 82: 2565-2578, 1999.

16. Ewart WR and Wingate DL. Central representation and opoid modulation of gastric mechanoreceptor activity in the rat. Am $J$ Physiol Gastrointest Liver Physiol 244: G27-G32, 1983.

17. Ewart WR and Wingate DL. Central representation of arrival of nutrient in the duodenum. Am $J$ Physiol Gastrointest Liver Physiol 246: G750-G756, 1984.

18. Foster LA, Nakamura $\mathbf{K}$, Greenberg $\mathbf{D}$, and Norgren $\mathbf{R}$. Intestinal fat differentially suppresses sham feeding of different gustatory stimuli. Am J Physiol Regulatory Integrative Comp Physiol 270: R1122-R1125, 1996.

19. Fulwiler CE and Saper CB. Subnuclear organization of the efferent connections of the parabrachial nucleus in the rat. Brain Res Rev 7: 229-259, 1984.

20. Giza BK, Deems RO, Vanderweele DA, and Scott TR. Pancreatic glucagon suppresses gustatory responsiveness to glucose. Am J Physiol Regulatory Integrative Comp Physiol 265: R1231R1237, 1993.

21. Giza BK and Scott TR. Intravenous insulin infusions in rat decrease gustatory-evoked responses to sugars. Am J Physiol Regulatory Integrative Comp Physiol 252: R994-R1002, 1987.

22. Giza BK, Scott TR, and Antonucci RF. Effect of cholecystokinin on taste responsiveness in rats. Am $J$ Physiol Regulatory Integrative Comp Physiol 258: R1371-R1379, 1990. 
23. Giza BK and Scott TR. Blood glucose selectively affects tasteevoked activity in rat nucleus tractus solitarius. Physiol Behav 31: 643-650, 1983.

24. Giza BK, Scott TR, and Vanderweele DA. Administration of satiety factors and gustatory responsiveness in the nucleus tractus solitarius of the rat. Brain Res Bull 28: 637-639, 1992.

25. Glenn JF. Gastric Modulation of Gustatory Afferent Activity. Durham, NC: Duke Univ., 1975.

26. Glenn JF and Erickson RP. Gastric modulation of gustatory afferent activity. Physiol Behav 16: 561-568, 1976.

27. Grill HJ and Kaplan JM. Caudal brainstem participates in the distributed neural control of feeding. In: Handbook of Behavioral Neurobiology. New York: Plenum, 1990, vol. 10, p. 125-49.

28. Grill HJ, Spector AC, Schwartz GJ, Kaplan JM, and Flynn FW. Evaluating taste effects on ingestive behavior. In: Feeding and Drinking. New York: Elsevier, 1987, p. 151-188.

29. Grill HJ, Friedman MI, Norgren R, Scalera G, and Seeley R. Parabrachial nucleus lesions impair feeding response elicited by 2,5-anhydro-D-mannitol. Am $J$ Physiol Regulatory Integrative Comp Physiol 268: R676-R682, 1995.

30. Grill HJ and Norgren R. Chronically decerebrate rats demonstrate satiation but not bait shyness. Science 201: 267-269, 1978.

31. Guthmann A and Herbert H. Distribution of metabotropic glutamate receptors in the parabrachial and Kolliker-fuse nuclei of the rat. Neuroscience 89: 873-881, 1999.

32. Gyetvai B and Bardos G. Modulation of taste reactivity by intestinal distension in rats. Physiol Behav 66: 529-535, 1999.

33. Hajnal A, Takenouchi K, and Norgren R. Effect of intraduodenal lipid on parabrachial gustatory coding in awake rats. J Neurosci 19: 7182-7190, 1999.

34. Halsell CB and Travers SP. Anterior and posterior oral cavity responsive neurons are differentially distributed among parabrachial subnuclei in rat. J Neurophysiol 78: 920-938, 1997.

35. Herbert $\mathbf{H}$ and Saper CB. Cholecystokinin-, galanin-, and corticotropin-releasing factor-like immunoreactive projections from the nucleus of the solitary tract to the parabrachial nucleus in the rat. J Comp Neurol 293: 581-598, 1990.

36. Hermann GE and Rogers RC. Convergence of vagal and gustatory afferent input within the parabrachial nucleus of the rat. J Auton Nerv Syst 13: 1-17, 1985.

37. Hermann GE, Kohlerman NJ, and Rogers RC. Hepaticvagal and gustatory afferent interactions in the brainstem of the rat. J Auton Nerv Syst 9: 477-495, 1983.

38. Kandel ER, Schwartz JH, and Jessell TM. Principles of Neural Science (4th ed.). New York: McGraw Hill, 2000, p. 207-251.

39. Kaplan JM, Siemers W, and Grill HJ. Ingestion, gastric fill, and gastric emptying before and after withdrawal of gastric contents. Am J Physiol Regulatory Integrative Comp Physiol 267: R1257-R1265, 1994.

40. Karimnamazi H. Organization of Oral and Gastric Representation in the Parabrachial Nucleus of the Rat. Columbus, OH: The Ohio State Univ., 1998.

41. Karimnamazi $\mathbf{H}$ and Travers JB. Differential projections from gustatory responsive regions of the parabrachial nucleus to the medulla and forebrain. Brain Res 813: 283-302, 1998.
42. Kelly A and Watts AG. The region of the parabrachial nucleus is a major target of dehydration-sensitive $\mathrm{CRH}$ neurons in the rat lateral hypothalamic area. J Comp Neurol 394: 48-63, 1998.

43. McCaughey SA and Scott TR. Rapid induction of sodium appetite modifies taste-evoked activity in the rat nucleus of the solitary tract. Am J Physiol Regulatory Integrative Comp Physiol 279: R1121-R1131, 2000.

44. Nishijo $\mathbf{H}$ and Norgren R. Parabrachial gustatory neural activity during licking by rats. J Neurophysiol 66: 974-985, 1991

45. Nishijo $\mathbf{H}$ and Norgren R. Parabrachial neural coding of taste stimuli in awake rats. $J$ Neurophysiol 78: 2254-2268, 1997.

46. Norgren R. Projections from the nucleus of the solitary tract in rat. Neuroscience 3: 207-218, 1978.

47. Norgren R. Gustatory system. In: The Rat Nervous System. San Diego, CA: Academic, 1995, p. 751-771.

48. Pagliassotti MJ and Cherrington AD. Regulation of net hepatic glucose uptake in vivo. Ann Rev Physiol 54: 847-860, 1992.

49. Phillips RJ and Powley TL. Gastric volume rather than nutrient content inhibits food intake. Am $J$ Physiol Regulatory Integrative Comp Physiol 271: R766-R779, 1996.

50. Reilly S, Grigson PS, and Norgren R. Parabrachial nucleus lesions and conditioned taste aversion: evidence supporting an associative deficit. Behav Neurosci 107: 1005-1017, 1993.

51. Rolls ET. Taste and olfactory processing in the brain and its relation to the control of eating. Crit Rev Neurobiol 11: 263-287, 1997.

52. Saper CB. Central autonomic system. In: The Rat Nervous System. San Diego, CA: Academic, 1995, p. 107-135.

53. Scharrer E, Lutz TA, and Rossi R. Coding of metabolic information by hepatic sensors controlling food intake. In: Liver Innervation. New York: Libbey, 1996, p. 381-388.

54. Seeley RJ, Grill HJ, and Kaplan JM. Neurological dissociation of gastrointestinal and metabolic contributions to meal size control. Behav Neurosci 108: 347-352, 1994

55. Smith GP. Pregastic and gastric satiety. In: Satiation: From Gut to Brain. New York, NY: Oxford Univ Press, 1998, p. 10-39.

56. Spector AC. Gustatory function in the parabrachial nuclei: implications from lesion studies in rats. Rev Neurosci 6: 143$175,1995$.

57. Staddon JER and Zanutto BS. Feeding dynamics. In: The Functional Behaviorism of Robert C. Bolles: Learning, Motivation and Cognition. Washington, DC: Am Psychol Assoc, 1997, chapt. 7.

58. Suemori K, Kobashi M, and Adachi A. Effects of gastric distension and electrical stimulation of dorsomedial medulla on neurons in parabrachial nucleus of rats. J Auton Nerv Syst 48: 221-229, 1994

59. Travers JB, Travers SP, and Norgren R. Gustatory neural processing in the hindbrain. Ann Rev Neurosci 10: 595-632, 1987.

60. Travers SP, Pfaffmann C, and Norgren R. Convergence of lingual and palatal gustatory neural activity in the nucleus of the solitary tract. Brain Res 365: 305-320, 1986.

61. Travers SP and Smith DV. Responsiveness of neurons in the hamster parabrachial nuclei to taste mixtures. J Gen Physiol 84: $221-250,1984$ 